\title{
Nanofat and Platelet Rich Plasma to Enhance Recovery and Minimize Risk of Recurrence after Endoscopic Carpal Tunnel Release
}

\author{
Michael J. Fitzmaurice \\ Fitzmaurice Hand Institute, Scottsdale, AZ, USA \\ Email:mfitz70@me.com
}

How to cite this paper: Fitzmaurice, M.J. (2019) Nanofat and Platelet Rich Plasma to Enhance Recovery and Minimize Risk of Recurrence after Endoscopic Carpal Tunnel Release. Modern Plastic Surgery, 9, 8-13. https://doi.org/10.4236/mps.2019.91002

Received: October 22, 2018

Accepted: December 26, 2018

Published: December 29, 2018

Copyright $\odot 2019$ by author and Scientific Research Publishing Inc. This work is licensed under the Creative Commons Attribution International License (CC BY 4.0).

http://creativecommons.org/licenses/by/4.0/

\begin{abstract}
Carpal tunnel release is one of the most common and surgery procedures performed. Complications and recurrence of the condition can occur up to $20 \%$ of cases. We describe a technique of utilizing the nanofat and platelet rich plasma to successfully enhance healing and minimize risk of recurrence after endoscopic carpal tunnel release. This patient had exceptionally fast recovery, resuming work in one day and excellent grip strength and a full functioning level at his two-week follow-up. After one year he continues to demonstrate a complete resolution of symptoms and full function without any evidence of recurrence or complications.
\end{abstract}

\section{Keywords}

Carpal Tunnel, Nanofat, Platelet Rich Plasma

\section{Introduction}

Carpal tunnel syndrome is the most common nerve compression disorder in the upper extremity. The prevalence of this condition is as high as $7.8 \%$ within the United States working population [1]. The incidence of carpal tunnel surgery is 108 per 100,000 person-years [2]. Complications and failures can occur in 3\% $19 \%$ of patients undergoing primary carpal tunnel release [3] [4]. Revision carpal tunnel release may be required in up to $12 \%$ of these patients [5] [6]. Nancollas et al. reported $57 \%$ of patients noted a return of preoperative symptoms within 2 years after carpal tunnel surgery [7]. Causes for a failure of the primary surgery and subsequent recurrence include an incomplete release of the transverse carpal ligament, adhesions of the median nerve and tenosynovitis [8]. Scarring around the nerve is the most difficult condition to treat as this often requires neurolysis 
and typically has a poor outcome compared to the results after the primary surgery due to the recurrence of additional scar tissue [9]. This article describes a novel technique of utilizing autologous fat tissue (nanofat) and platelet rich plasma (NeuroRejuvenation ${ }^{\varpi}$ ) around the nerve and in the wound at the time of the primary procedure to enhance wound healing and decrease the risk of scar tissue and subsequent recurrence.

\section{Case Report}

Informed consent was obtained from the patient prior to reporting this case of a 58-year-old male with a history of numbness for ten years. He describes the symptoms worsening over the last couple of years. He had failed conservative management. On examination, he had decreased sensation to the median nerve distribution as well as thenar atrophy. An ultrasound examination was performed which demonstrated enlargement of the median nerve within the carpal tunnel measuring $18 \mathrm{~mm}^{2}$. This measurement was consistent with a severe carpal tunnel syndrome. We did not demonstrate any abnormal anatomy such as a bifid median nerve or a persistent median artery which would affect our visualization during an endoscopic release. A nerve conduction study was also performed which demonstrated findings consistent with a severe right carpal tunnel syndrome with a sensory distal motor latency of $6.55 \mathrm{~ms}$ (milliseconds) and a distal motor latency of $8.35 \mathrm{~ms}$ (milliseconds). We discussed options and due to his severely lack of improvement with any conservative management he wished to proceed with surgical intervention.

The patient underwent an endoscopic carpal tunnel release (EndoTech $\left.{ }^{\circledR}\right)$ under local anesthesia. Fat harvest was performed via liposuction from the patient's abdomen with tumescent fluid under local anesthesia. This tissue was then placed into two syringes and using connectors we repeatedly pressed this tissue from one syringe to the next 20 times. The mechanically emulsified fa tissue obtained was then placed in the centrifuge (MediKhan). The resulting fat tissue was then ready for into the wound and around the nerve using an 18-gauge Angiocath needle. We also obtained whole blood from an intravenous cannula. This blood was placed in a centrifuge (Emcyte) to obtain the platelet rich plasma which was placed around the nerve and in the wound using an 18-gauge Angiocath needle. The carpal tunnel release site and abdominal wounds were then dressed with sterile dressings. He was discharged with a guideline for utilizing nonnarcotic pain medications.

The patient was then seen for a follow-up visit 15 days after the procedure. He did not require any prescription pain medications and was able to resume work the next day which involved a desk job activity. On examination, he had minimal discomfort and had full range of motion with a grip strength of 65 pounds. $\mathrm{He}$ did not require any formal therapy and could perform unrestricted activities. He was then followed up after 13 months via a phone call at which time he completed a quick-evaluation. His QuickDash score was 0 out of a possible with 100 with 0 being no symptoms or limited function and 100 being the worst possible 
symptoms and limitation of function. He rated his overall experience as very satisfied, denying any numbness or discomfort to the right hand. During his treatment course there was no evidence of any complications or infections.

\section{Discussion}

Failure after the initial carpal tunnel release can occur in up to $19 \%$ of patients which may require revision surgery [3] [4]. Secondary procedures for recurrent carpal tunnel syndrome often have less improvement than after a primary surgery. Improvement can occur in $80 \%$ of patients after revision surgery, however, up to $20 \%$ may remain unchanged and $10 \%$ of who may require a third operation [10]. Authors have reported up to $40 \%$ poor results and $95 \%$ with persistent symptoms after re-exploration [11] [12]. Operative findings of circumferential fibrosis around the median nerve often lead to a poor result postoperatively [10]. Several procedures and various implants have been used to minimize the risk of adhesions during peripheral nerve surgery. These include fat tissue transfer, hypothenar fat pad, collagen materials, amniotic tissue, Seprafilm and Interceed [13]-[24]. Authors have recently utilized a nerve barrier during a primary procedure with a significant improvement in outcomes and reduction in recurrence rate [25]. Another group is currently using interceed to cover the median nerve during primary carpal tunnel release as they have so far experienced excellent results [19]. The hypothenar fat pad is also being used during the primary surgery for end stage carpal tunnel syndrome to improve nerve regeneration and decrease risk of recurrence [26]. In a prospective study comparing an open carpal tunnel release with and without hypothenar fat pad, there was improved function and symptom score on the BCTQ with those patients having the additional fat pad placed over the nerve compared to those who did not have this additional procedure, but this was not statistically significant due to the low number of patients in the study [22].

This case report demonstrates the safety and effectiveness of utilizing a nanofat technique along with platelet rich plasma to enhance the healing and minimize risk of recurrence after a carpal tunnel release surgery. This patient was able to resume work activities the next day and by first follow-up had excellent grip strength and minimal discomfort. His grip strength measured 65 pounds which is greater than the 20 pounds required for functional activity. After 1 year follow-up he demonstrated lowest possible score possible (least amount of symptoms and highest level of function) on his QuickDash patient rated outcome questionnaire and was doing exceptionally well with no evidence of recurrence. Post-operative scar tissue is the most common cause for failure and recurrence of carpal tunnel syndrome. This procedure improves wound healing and stimulates faster recovery while decreasing the likelihood of post-operative scar tissue. The technique presented here improves outcomes after carpal tunnel release and decreases the costs and morbidity associated with recurrence carpal tunnel syndrome. 


\section{Conclusion}

In conclusion we present a technique of utilizing autologous tissue including nanofat and platelet rich plasma to enhance the recovery and decrease the risk of recurrence following a carpal tunnel release. This technique is a very safe and effective technique to enhance the healing and minimize risk of complications or revision following an extremely common surgical procedure. We are currently evaluating this procedure with a case control series to compare the endoscopic technique with and without the nanofat and platelet rich plasma technique.

\section{Conflicts of Interest}

The author declares no conflicts of interest regarding the publication of this paper.

\section{References}

[1] Dale, A.M., Harris-Adamson, C., Rempel, D., et al. (2013) Prevalence and Incidence of Carpal Tunnel Syndrome in US Working Populations: Pooled Analysis of Six Prospective Studies. Scandinavian Journal of Work, Environment \& Health, 39, 495-505. https://doi.org/10.5271/sjweh.3351

[2] English, J.H.J. and Gwynne-Jones, D.P. (2015) Incidence of Carpal Tunnel Syndrome Requiring Surgical Decompression: A 10.5-Year Review of 2309 Patients. YJHSU, 40, 2427-2434.

[3] Kulick, M.I., Gordillo, G., Javidi, T., Kilgore, E.S. and Newmayer, W.L. (1986) Long-Term Analysis of Patients Having Surgical Treatment for Carpal Tunnel Syndrome. The Journal of Hand Surgery, 11, 59-66. https://doi.org/10.1016/S0363-5023(86)80104-6

[4] Botte, M.J., von Schroeder, H.P., Abrams, R.A. and Gellman, H. (1996) Recurrent Carpal Tunnel Syndrome. Hand Clinics, 12, 731-743.

[5] Stütz, N., Gohritz, A., van Schoonhoven, J. and Lanz, U. (2006) Revision Surgery after Carpal Tunnel Release-Analysis of the Pathology in 200 Cases during a 2 Year Period. Journal of Hand Surgery (European Volume), 31, 68-71. https://doi.org/10.1016/J.JHSB.2005.09.022

[6] Hulsizer, D.L., Staebler, M.P., Weiss, A.P. and Akelman, E. (1998) The Results of Revision Carpal Tunnel Release Following Previous Open versus Endoscopic Surgery. The Journal of Hand Surgery, 23, 865-869. https://doi.org/10.1016/S0363-5023(98)80164-0

[7] Nancollas, M.P., Peimer, C.A., Wheeler, D.R. and Sherwin, F.S. (1995) Long-Term Results of Carpal Tunnel Release. Journal of Hand Surgery (European Volume), 20, 470-474. https://doi.org/10.1016/S0266-7681(05)80155-X

[8] Bagatur, A.E. (2002) Analysis of the Causes of Failure in Carpal Tunnel Syndrome Surgery and the Results of Reoperation. Acta Orthopaedica et Traumatologica Turcica, 36, 346-353.

[9] Stang, F., Stütz, N., Lanz, U., van, J.S. and Prommersberger, K.J. (2008) Results after Revision Surgery for Carpal Tunnel Release. Handchirurgie - Mikrochirurgie - Plastische Chirurgie, 40, 289-293. https://doi.org/10.1055/s-2008-1038611

[10] Jones, N.F., Ahn, H.C. and Eo, S. (2012) Revision Surgery for Persistent and Recurrent Carpal Tunnel Syndrome and for Failed Carpal Tunnel Release. Plastic and 
Reconstructive Surgery, 129, 683-692.

https://doi.org/10.1097/PRS.0b013e3182402c37

[11] O’Malley, M.J., Evanoff, M., Terrono, A.L. and Millender, L.H. (1992) Factors that Determine Reexploration Treatment of Carpal Tunnel Syndrome. YJHSU, 17, 638-641.

[12] Strasberg, S.R., Novak, C.B., Mackinnon, S.E. and Murray, J.F. (1994) Subjective and Employment Outcome Following Secondary Carpal Tunnel Surgery. Annals of Plastic Surgery, 32, 485-489. https://doi.org/10.1097/00000637-199405000-00008

[13] Gaspar, M.P., Kane, P.M., Vosbikian, M.M., Ketonis, C. and Rekant, M.S. (2017) Neurolysis with Amniotic Membrane Nerve Wrapping for Treatment of Secondary Wartenberg Syndrome: A Preliminary Report. The Journal of Hand Surgery (Asian-Pacific Volume), 22, 222-228. https://doi.org/10.1142/S0218810417200015

[14] Nassar, W.A.M. and Atiyya, A.N. (2014) New Technique for Reducing Fibrosis in Recurrent Cases of Carpal Tunnel Syndrome. Hand Surgery, 19, 381-387. https://doi.org/10.1142/S0218810414500312

[15] Sanders, R.J., Hammond, S.L. and Rao, N.M. (2007) Observations on the Use of Seprafilm $^{\circledast}$ on the Brachial Plexus in 249 Operations for Neurogenic Thoracic Outlet Syndrome. Hand, 2, 179-183. https://doi.org/10.1007/s11552-007-9044-4

[16] Topsakal, C., Akpolat, N., Erol, F.S., et al. (2004) Seprafilm Superior to Gore-Tex in the Prevention of Peridural Fibrosis. Journal of Neurosurgery, 101, 295-302.

https://doi.org/10.3171/jns.2004.101.2.0295

[17] Subach, B.R. and Copay, A.G. (2015) The Use of a Dehydrated Amnion/Chorion Membrane Allograft in Patients Who Subsequently Undergo Reexploration after Posterior Lumbar Instrumentation. Advances in Orthopedics, 2015, Article ID: 501202. https://doi.org/10.1155/2015/501202

[18] Wallach, F., Richou, J., Genestet, M. and Le Nen, D. (2008) Free Dermal Fat Graft for Coverage of the Median Nerve Following Failed Carpal Tunnel Release. Chirurgie de la Main, 27, 208-215. https://doi.org/10.1016/j.main.2008.08.011

[19] Loick, J., Joosten, U. and Lücke, R. (1997) Implantation of Oxidized, Regenerated Cellulose for Prevention of Recurrence in Surgical Therapy of Carpal Tunnel Syndrome. Handchir Mikrochir Plast Chir, 29, 209-213.

[20] Kokkalis, Z.T., Mavrogenis, A.F., Ballas, E.G., Papagelopoulos, P.J. and Soucacos, P.N. (2015) Collagen Nerve Wrap for Median Nerve Scarring. Orthopedics, 38, 117-121. https://doi.org/10.3928/01477447-20150204-04

[21] Ohsumi, H., Hirata, H., Nagakura, T., et al. (2005) Enhancement of Perineurial Repair and Inhibition of Nerve Adhesion by Viscous Injectable Pure Alginate Sol. Plastic and Reconstructive Surgery, 116, 823-830. https://doi.org/10.1097/01.prs.0000176893.44656.8e

[22] Kanchanathepsak, T., Wairojanakul, W., Phakdepiboon, T., Suppaphol, S., Watcharananan, I. and Tawonsawatruk, T. (2017) Hypothenar Fat Pad Flap vs. Conventional Open Release in Primary Carpal Tunnel Syndrome: A Randomized Controlled Trial. World Journal of Orthopedics, 8, 846-852.

https://doi.org/10.5312/wjo.v8.i11.846

[23] Kokkalis, Z.T. and Mavrogenis, A.F. (2016) Median Nerve Biodegradable Wrapping: Clinical Outcome of 10 Patients. Acta Orthopaedica Belgica, 82, 351-357.

[24] Sobti, S., Grover, A., John, B.P.S., Grewal, S.S. and George, U.B. (2018) Prospective Randomized Comparative Study to Evaluate Epidural Fibrosis and Surgical Outcome in Patients Undergoing Lumbar Laminectomy with Epidural Autologous Free 
Fat Graft or Gelfoam: A Preliminary Study. International Journal of Applied and Basic Medical Research, 8, 71-75. https://doi.org/10.4103/ijabmr.IJABMR_349_17

[25] Lorusso, D. and Giliberti, A. (2016) Carpal Tunnel Release: Avoiding Complications with Layer Shield Matrix. Jurnalul de Chirurgie, 12, 51-53.

[26] Lattré, T., Brammer, S., Parmentier, S. and Van Holder, C. (2016) Hypothenar Fat Pad Flap Surgery for End Stage and Recurrent Carpal Tunnel Syndrome. Hand Surgery \& Rehabilitation, 35, 348-354. https://doi.org/10.1016/j.hansur.2016.08.003 